\title{
Correction to: Risk factors for the progression of finger interphalangeal joint osteoarthritis: a systematic review
}

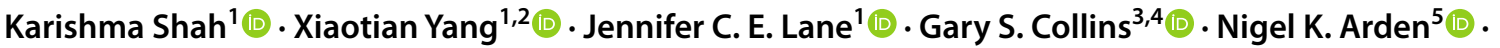 \\ Dominic Furniss ${ }^{1,4}$ (1) Stephanie R. Filbay ${ }^{5,6}$ (D)
}

(c) The Author(s) 2021

\section{Correction to: \\ Rheumatology International (2020) 40:1781-1792 \\ https://doi.org/10.1007/s00296-020-04687-1}

In the original article published, the references are cited incorrectly in Tables 1,2 and 3. The correct information is given below:

The correct citation number for the study Plato et al. is reference number 39: Plato CC, Norris AH. Osteoarthritis of the hand: longitudinal studies. Am J Epidemiol. 1979;110(6):740-746.

The correct citation number for the study Kallman et al. is reference number 37: Kallman DA, et al. The longitudinal course of hand osteoarthritis in a male population. Arthritis Rheum. 1990;33(9):1323-1332.

The correct citation number for the study Busby et al. is reference number 38: Busby J, et al. A longitudinal study of osteoarthritis of the hand: the effect of age. Ann Hum Biol. 1991;18(5):417-424.

The correct citation number for the study Kalichman et al. is reference number 43: Kalichman L, et al. Repeated measurement study of hand osteoarthritis in an apparently healthy Caucasian population. Am J Hum Biol. 2005;17(5):611-621.

The correct citation number for the study Kalichman et al. is reference number 44: Kalichman L, et al. Epiphyseal expansion in hand bones: association with age, sex, and hand osteoarthritis. Osteoarthr Cartil. 2008;16(5):560-565.

The correct citation number for the study Hoeven et al. is reference number 40: Hoeven TA, et al. Association of atherosclerosis with presence and progression of osteoarthritis: the Rotterdam Study. Ann Rheum Dis. 2013;72(5):646-651.

The correct citation number for the study Haugen et al. is reference number 41: Haugen IK, et al. The prevalence,

The original article can be found online at https://doi.org/10.1007/ s00296-020-04687-1.

Karishma Shah

karishma.shah@ndorms.ox.ac.uk

Xiaotian Yang

yangxiaotian0821@hotmail.com

Jennifer C. E. Lane

jennifer.lane@ndorms.ox.ac.uk

Gary S. Collins

gary.collins@csm.ox.ac.uk

Nigel K. Arden

nigel.arden@ndorms.ox.ac.uk

Dominic Furniss

dominic.furniss@ndorms.ox.ac.uk

Stephanie R. Filbay

stephanie.filbay@unimelb.edu.au

1 Nuffield Department of Orthopaedics, Rheumatology and Musculoskeletal Sciences, Botnar Research Centre, University of Oxford, Oxford, UK
2 Department of Rehabilitation Medicine, West China Hospital, Sichuan University, Chengdu, China

3 Nuffield Department of Orthopaedics, Rheumatology and Musculoskeletal Sciences, Centre for Statistics in Medicine, University of Oxford, Oxford, UK

4 National Institute for Health Research Oxford Biomedical Research Centre, John Radcliffe Hospital, Oxford, UK

5 Nuffield Department of Orthopaedics, Rheumatology and Musculoskeletal Sciences, Centre for Sport, Exercise and Osteoarthritis Research Versus Arthritis, University of Oxford, Oxford, UK

6 Department of Physiotherapy, Centre for Health Exercise and Sports Medicine, University of Melbourne, Melbourne, Australia 
incidence, and progression of hand osteoarthritis in relation to body mass index, smoking, and alcohol consumption. J Rheumatol. 2017;44(9):1402-1409.

The correct citation number for the study Marshall et al. is reference number 42: Marshall M, et al. Metabolic risk factors and the incidence and progression of radiographic hand osteoarthritis: a population-based cohort study. Scand J Rheumatol. 2019;48(1):52-63.

Open Access This article is licensed under a Creative Commons Attribution 4.0 International License, which permits use, sharing, adaptation, distribution and reproduction in any medium or format, as long as you give appropriate credit to the original author(s) and the source, provide a link to the Creative Commons licence, and indicate if changes were made. The images or other third party material in this article are included in the article's Creative Commons licence, unless indicated otherwise in a credit line to the material. If material is not included in the article's Creative Commons licence and your intended use is not permitted by statutory regulation or exceeds the permitted use, you will need to obtain permission directly from the copyright holder. To view a copy of this licence, visit http://creativecommons. org/licenses/by/4.0/.

Publisher's Note Springer Nature remains neutral with regard to jurisdictional claims in published maps and institutional affiliations. 